\title{
Hyperosmolar Non-ketotic Diabetic Coma: with Particular Reference to Vascular Complications
}

\author{
MICHAEL J. WHELTON, DAVID WALDE, C. W. H. HAVARD
}

British Medical fournal, 1971, 1, 85-86

\begin{abstract}
Summary
Two West Indian men with no previous history of diabetes mellitus developed hyperosmolar non-ketotic diabetic coma. Intra-abdominal catastrophes secondary to mesenteric thrombosis played a major part in the death of these patients, in both of whom control of the hyperosmolar state had been achieved. Both patients had evidence of infarction of intestine at necropsy. Vascular thromboses are a major complication of this form of coma and must be considered when such patients develop signs of an acute abdomen.
\end{abstract}

\section{Introduction}

Hyperosmolar non-ketotic coma is a recognized complication of diabetes mellitus (Di Benedetto, Crocco, and Soscia, 1965; Oakley, Pyke, and Taylor, 1968; Tyler, 1968). It has generally been considered to complicate diabetes in the middle-aged or elderly (Lucas, Grant, Daily, and Reaven, 1963) but is being increasingly reported in other age groups (Ehrlich and Bain, 1967; Pyke, 1969). The possibility of racial predisposition to the disorder has recently been discussed (Pyke, 1969). Intravascular thrombosis may complicate this type of coma, but its occurrence has probably not been sufficiently well recognized. The cases of two West Indian men who developed mesenteric thromboses during treatment for hyperosmolar coma are reported.

\section{Case 1}

In March 1969 a 63-year-old West Indian man was admitted to hospital in coma. In 1968 a diagnosis of polyarteritis had been made when he developed fever, chest pain, pleural effusion, weight loss, and arthralgia. At that time the E.S.R. was $100 \mathrm{~mm} /$ hour, the blood urea concentration was $26 \mathrm{mg} / 100 \mathrm{ml}$. A random blood sugar level was $100 \mathrm{mg} / 100 \mathrm{ml}$. A muscle biopsy was normal. He was treated with prednisolone $60 \mathrm{mg}$ daily, later reduced to $30 \mathrm{mg}$ daily. Creatinine clearance was $58 \mathrm{ml} / \mathrm{min}$, later falling to $35 \mathrm{ml} / \mathrm{min}$, but in January 1969 it had risen to $148 \mathrm{ml} / \mathrm{min}$.

Five days before his final admission to hospital he became thirsty and depressed, and lost his appetite. The night before admission he was drowsy and confused, but he passed urine normally and was not vomiting. On admission he was unconscious, severely dehydrated, and unresponsive to painful stimuli. His blood pressure was $60 \mathrm{~mm} \mathrm{Hg}$ systolic, the extremities were cold, the abdomen was soft and not tender. His reflexes were brisk, with normal muscle tone. The urine contained $2 \%$ glucose but no ketones.

Investigations-Blood sugar $1,280 \mathrm{mg} / 100 \mathrm{ml}$; blood urea $184 \mathrm{mg} / 100 \mathrm{ml}$; serum sodium $137 \mathrm{mEq} / 1$., potassium $4.5 \mathrm{mEq} / 1$., chloride $109 \mathrm{mEq} / 1$; $\mathrm{pH} 7 \cdot 16$; standard bicarbonate $11.8 \mathrm{mEq} / 1$.,

\section{Royal Northern Hospital, London N.7}

MICHAEL J. WHELTON, M.D., M.R.C.P., Senior Medical Registrar (Present address: Gastrointestinal Unit, Western General Hospital, Edinburgh, EH4 2XU)

DAVID WALDE, M.B., B.S., House Physician (Present address: Guy's Hospital, London S.E.1)

C. W. H. HAVARD, D.M., F.R.C.P., Consultant Physician
$\mathrm{PCO}_{2} 31 \mathrm{~mm}$; base excess $15.5 \mathrm{mEq} / 1$; plasma cortisol (on admission) $60 \mu \mathrm{g} / 100 \mathrm{ml}$; haemoglobin $17.7 \mathrm{~g} / 100 \mathrm{ml}$; P.C.V. $59 \%$; serum acetone nil. Plasma osmolality (estimated) $482 \mathrm{mOsm} / 1$.

On admission he was given 80 units of soluble insulin intravenously and 80 units intramuscularly. In addition, $100 \mathrm{mg}$ of hydrocortisone was given intravenously and $100 \mathrm{mg}$ intramuscularly. Fluid replacement with hypotonic saline and potassium was initiated. One hour after admission he was confused but responded to stimuli, and five hours after admission the blood sugar had fallen to $838 \mathrm{mg} / 100 \mathrm{ml}$. Shortly afterwards, however, his abdomen became distended and bowel sounds could not be heard. Fresh blood was aspirated from his stomach. He died soon afterwards following a cardiac arrest. At necropsy the mesenteric artery was thrombosed, the entire jejunum and the upper third of the ileum were infarcted, and the gut lumen was full of haemorrhagic exudate. There was embolic obstruction of the right pulmonary artery. The adrenal glands were normal.

\section{Case 2}

In June 1969 a 53-year-old West Indian man was admitted to hospital. He had suffered from hypertension for two years, but the blood pressure had been satisfactorily controlled with methyldopa, bethanidine, chlorothiazide, and spironolactone. A creatinine clearance in 1967 was $92 \mathrm{ml} / \mathrm{min}$. He was brought to hospital, having been found semicomatose in his home. He had been unwell for one week, and in the 24 hours before admission had complained of thirst, nausea, abdominal pain, and polyuria. There was no vomiting. A friend had attempted to administer a soapand-water enema with a Foley catheter. On admission he was semiconscious, the blood pressure was $100 / 60$, and there was generalized distension of the abdomen with slight epigastric tenderness but no rigidity. Tendon reflexes and muscle tone were nor$\mathrm{mal}$. There was fresh blood on the finger stall on rectal examination.

The results of the investigations are given in the Table.

Case 2.* Results of Investigations

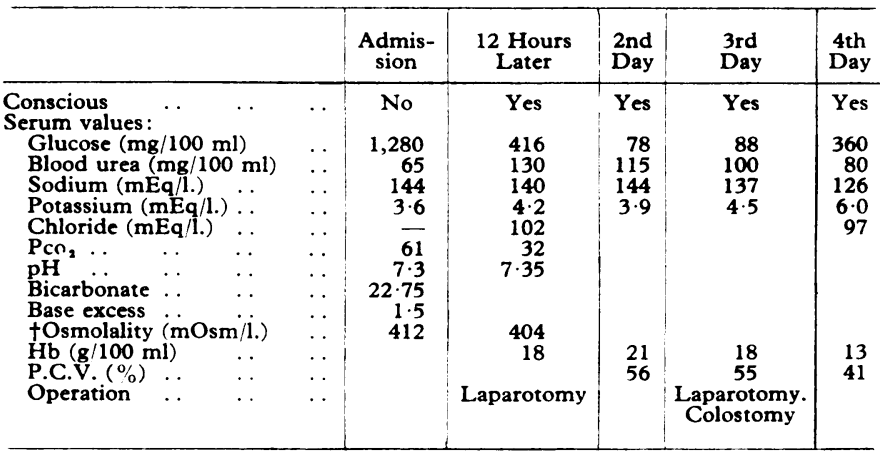

- Patient died on 5 th hospital day.

+Estimated from blood glucose, sodium, and potassium levels.

He was given 100 units of soluble insulin intravenously and 80 units subcutaneously. During his stay in hospital he received a total of 1,050 units of soluble insulin of which 580 units were given in the first 12 hours. The stomach was intubated and continuous gastric suction instituted. Parenteral antibiotic therapy was given. He received 7.5 litres of intravenous fluids (consisting of half normal saline and 2 units of whole blood). During this time the patient had two grand mal epileptic attacks and at other times there was also non-specific twitching. Hypocalcaemia was corrected with intravenous calcium gluconate. Though he was 
fully conscious 12 hours after admission there was gross abdominal distension, bowel sounds were poor, and he was passing frank blood per rectum. At laparotomy an oedematous reddened area was observed at the rectosigmoid junction, the histology of which showed gangrenous change in the mucosa. As no definite obstruction was found and the small bowel appeared healthy, the abdomen was closed. Postoperatively his diabetes was well controlled (see Table). The abdomen, however, remained distended and signs of intestinal obstruction persisted. A second laparotomy was carried out on the evening of the third day of admission. The rectum was inflamed and oedematous and a left iliac loop colostomy was performed. His condition deteriorated postoperatively and he died early on the fourth hospital day.

At necropsy there was a haemoperitoneam. Both large and small intestines were oedematous and many small haemorrhagic lesions were scattered in the mesentery of the small bowel. The liver showed evidence of early cirrhosis. The large bowel from the mid-transverse colon to the rectum showed established post-mortem autolytic changes.

\section{Discussion}

While abdominal complications are not uncommon in diabetic ketosis (McKittrick, 1933; Hirsch, 1960; Katz and Spiro, 1966) apart from pancreatitis (Davidson, 1964) they do not appear to have been reported with any frequency in hyperosmolar coma. Thrombotic complications were noted in two of the 16 patients with hyperosmolar coma reported by Pyke (1969); in one a femoral artery thrombus was removed surgically, but the other died with pulmonary artery thrombosis. Both of our patients developed intra-abdominal complications due to mesenteric thromboses. One developed an acute abdomen with massive gastrointestinal bleeding. At necropsy the jejunum and the upper third of the ileum were haemorrhagic and showed evidence of recent infarction due to venous thrombosis. In addition, a pulmonary embolism was present. The other developed an acute abdomen with moder- ate gastrointestinal bleeding. At the initial laparotomy a gangrenous area was found in the rectum, but as there was no apparent mechanical obstruction no bypass procedure was carried out. At a second laparotomy 36 hours later the area of infarction was more extensive and a colostomy was constructed. Despite this he continued to deteriorate. At necropsy multiple haemorrhages were present in the mesentery of the small intestine in addition to a moderate haemoperitoneum. There is little doubt that in both these patients the intra-abdominal catastrophes contributed to death.

When thromboses occur in intra-abdominal vessels they pose particularly difficult clinical problems in these patients. Laparotomy, though it carries a high risk, may need to be considered much more seriously than in patients with ketotic diabetic coma. The pathological features of the thrombosed vessels are non-specific. It is of interest that both the above patients were West Indians, as hyperosmolar coma appears to be relatively common in Jamaicans (Pyke, 1969).

We wish to thank Dr. R. R. A. Javaweera and Dr. P. Baxter for their help in the management of Case 2 and Dr. R. Bird and staff and Dr. M. Peters for their assistance.

\section{References}

Di Benedetto, R. J., Crocco, J. A., and Soscia, J. L. (1965). Archivcs of Internal Medicine, 116, 74

Davidson, A. I. G. (1964). British Medical fournal, 1, 356.

Ehrlich, R. M., and Bain, H. W. (1967). New England fournal of Medicine, 276, 683 .

Hirsch, M. L. (1960). Diabetes, 9, 94.

Katz, L. A., and Spiro, H. M. (1966). New England fournal of Medicine, $275,1350$.

Lucas, C. P., Grant, N., ,Daily, W. J., and Reaven, G. M. (1963). Lancet, $1,75$.

McKittrick, L. S. (1933). New England fournal of Medicine, 209, 1033.

Oakley, W. G., Pyke, D. A., and Taylor, K. W. (1968). Clinical Diabetes and its Biochemical Basis, p. 420. Oxford, Blackwell.

Pyke, D. A. (1969). Fournal of Clinical Pathology, 22, Suppl. No. 2, p. 57. Tyler, F. H. (1968). American fournal of Medicine, 45, 485.

\section{PRELIMINARY COMMUNICATIONS}

\section{Agglutinin Response to Pertussis Vaccination in the Child}

\author{
J. D. ABBOTT, N. W. PRESTON, R. I. MACKAY
}

British Medical fournal, 1971, 1, 86-88

\section{Summary}

Children were immunized with plain pertussis vaccine made by three manufacturers in 1967. After a primary course of three injections at monthly intervals, starting at 3-4 months of age, the agglutinin response was poor. Even after a "booster" dose, given five months later, not all of the vaccines had stimulated a response to all three pertussis agglutinogens.

Public Health Laboratory, Withington Hospital, Manchester 20 J. D. ABBOTT, M.D., M.R.C.PATH., Deputy Director

University of Manchester, Manchester M13 9PL

N. W. PRESTON, M.D., M.R.C.PATH., Senior Lecturer in Bacteriology

Hope Hospital, Salford 6, Lancs

R. I. MACKAY, M.B., M.R.C.P., Consultant Paediatrician
A further investigation with current vaccines of different kinds administered according to more than one schedule is recommended.

\section{Introduction}

The effectiveness of pertussis vaccination has been questioned in recent years. An investigation by the Public Health Laboratory Service (1969) showed that some of the vaccines used before or during 1967 were not very effective, as shown by a comparison of the attack rates in vaccinated and unvaccinated children. Perkins (1969) pointed out that these vaccines would "have been made, as bulk components, before 1966," and that vaccines made after 1966 have been modified by increasing their minimal potency requirement, as indicated by the mouse protection test, and also by including some of the prevalent type 1,3 strains in the vaccine.

We are reporting here on the agglutinin response of the child to the vaccines of three manufacturers which were made in April, June, and July of 1967, and each of which was stated to contain antigens 1,2 , and 3 .

\section{Materials and Methods}

Pertussis Vaccines.-The vaccines of three manufacturers $(\mathrm{X}, \mathrm{Y}$, and $\mathrm{Z}$ ) were used. The batches had been manufac- 